\title{
Temporal cross-correlations between air pollutants and outpatient visits for respiratory and circulatory system diseases in Fuzhou, China
}

Yu Jiang ${ }^{1 \dagger}$, Jiedong Chen ${ }^{1 \dagger}$, Chuancheng $\mathrm{Wu}^{1}$, Xin Lin², Quan Zhou², Shumi Ji', Shuangfeng Yang ${ }^{1}$, Xiaoyang Zhang ${ }^{2^{*}}$ and Baoying Liu ${ }^{1 *}$ (i)

\begin{abstract}
Background: Previous studies have suggested that there is an association between air pollutants and circulatory and respiratory diseases; however, relatively few have analyzed the association between air pollutants and outpatient visits based on the mortality, hospitalization rates, etc., especially in areas with relatively good air quality. Therefore, we conducted this study to research the association between air pollutants and outpatient visits in Fuzhou, China.

Methods: We used a generalized linear Poisson model to study the association between air pollution and outpatient visits for respiratory and circulatory diseases from 2016 to 2018 in Fuzhou, China.

Results: In the single pollutant model, nitrogen dioxide $\left(\mathrm{NO}_{2}\right)$ had a significant effect. For lag day 0 to lag day 5 , the effect decreased with every $10 \mu \mathrm{g} / \mathrm{L}$ increase in $\mathrm{NO}_{2}$. The daily maximum 8-h mean ozone $\left(\mathrm{O}_{3}-8 \mathrm{~h}\right)$ and upper respiratory outpatient visits were positively associated during the cold period [lag2, excess risk (ER) (95\% confidence interval (Cl)): $1.68 \%(0.44-2.94 \%)]$, while $\mathrm{O}_{3}-8 \mathrm{~h}$ and respiratory disease were positively associated during the warm period [lag5, ER (95\% Cl): 1.10\% (0.11-2.10\%) and lag4, ER (95\% Cl): 1.02\% (0.032-2.02\%)]. Similarly, particulate matter (PM) with an average aerodynamic diameter of less than $10 \mu \mathrm{m}\left(\mathrm{PM}_{10}\right)$ and lower respiratory diseases were positively associated during the warm period [lag0, ER (95\% Cl): 1.68\% (0.44-2.94\%)]. When the concentration of $\mathrm{O}_{3}-$ 8h was higher than $100 \mu \mathrm{g} / \mathrm{L}$, there was a positive effect on circulatory [lag5, ER (95\% Cl): $2.83 \%(0.65-5.06 \%)$, respiratory [lag5, ER (95\% Cl): 2.47\% (0.85-4.11\%)] and upper respiratory [lag5, ER (95\% Cl): 3.06\% (1.38-4.77\%)] outpatient visits. The variation in $\mathrm{O}_{3}-8 \mathrm{~h}$ changed slightly when we adjusted for other air pollutants, and after adjusting for $\mathrm{O}_{3}-8 \mathrm{~h}$, the ERs of the other air pollutants changed slightly. After adjusting for PM with an average aerodynamic diameter of less than $2.5 \mu \mathrm{m}\left(\mathrm{PM}_{2.5}\right)$, the ERs of the other air pollutants increased, and after adjusting for $\mathrm{NO}_{2}$, the ER of PM decreased.

(Continued on next page)
\end{abstract}

\footnotetext{
*Correspondence: Iby@mail.fjmu.edu.cn; sanny77@sina.com

${ }^{\dagger}$ Yu Jiang and Jiedong Chen contributed equally to this work.

'Department of Preventive Medicine, Fujian Provincial Key Laboratory of

Environment Factors and Cancer, Key Laboratory of Environment and Health,

School of Public Health, Fujian Medical University, Fuzhou, China

${ }^{2}$ Fuzhou Center for Disease Control and Prevention, Fuzhou, China
}

(c) The Author(s). 2020 Open Access This article is licensed under a Creative Commons Attribution 4.0 International License, which permits use, sharing, adaptation, distribution and reproduction in any medium or format, as long as you give appropriate credit to the original author(s) and the source, provide a link to the Creative Commons licence, and indicate if changes were made. The images or other third party material in this article are included in the article's Creative Commons licence, unless indicated otherwise in a credit line to the material. If material is not included in the article's Creative Commons licence and your intended use is not permitted by statutory regulation or exceeds the permitted use, you will need to obtain permission directly from the copyright holder. To view a copy of this licence, visit http://creativecommons.org/licenses/by/4.0/ The Creative Commons Public Domain Dedication waiver (http://creativecommons.org/publicdomain/zero/1.0/) applies to the data made available in this article, unless otherwise stated in a credit line to the data. 
(Continued from previous page)

Conclusion: Exposure to ambient $\mathrm{NO}_{2}, \mathrm{O}_{3}, \mathrm{PM}_{2.5}$ and $\mathrm{PM}_{10}$ was associated with an increase in respiratory and circulatory system-related outpatient visits in Fuzhou, China.

Keywords: Air pollution, Coastal area, Time-series analysis, Season

\section{Background}

Ambient air pollution is on the rise, with the most marked increases in rapidly developing and industrializing low-income and middle-income countries [1]. As the largest developing country, China has developed increasingly serious air quality problems, and air pollution issues are increasingly prominent. However, few Chinese cities have established citywide morbidity reporting systems, and there are few studies of China's coastal area $[2,3]$. Data revealing the association between air pollution and human health are limited in China, and the lack of fine particulate matter (average aerodynamic diameter of less than $\left.2.5 \mu \mathrm{m} ; \mathrm{PM}_{2.5}\right)$ and ozone $\left(\mathrm{O}_{3}\right)$ data from most Chinese cities further hinders the value of such studies [2]. According to the World Health Organization's (WHO's) air quality standards, the acceptable daily average concentrations of $\mathrm{PM}_{2.5}$ and $\mathrm{PM}_{10}$ (PM with an average aerodynamic diameter of less than $10 \mu \mathrm{m})$ are $25 \mu \mathrm{g} / \mathrm{m}^{3}$ and $50 \mu \mathrm{g} / \mathrm{m}^{3}$, respectively, and the 8 -h average concentration of $\mathrm{O}_{3}$ is $100 \mu \mathrm{g} / \mathrm{m}^{3}$ [4]. In China, even areas with relatively good air quality may not meet the WHO's air quality standard.

Previous studies have shown that air pollution and outpatient visits are likely associated with respiratory and circulatory diseases $[5,6]$. High pollutant concentrations can even increase the daily cardiovascular/respiratory death rates [7]. For example, $\mathrm{NO}_{2}$ may cause lung cancer [8], PM has been associated with increased blood pressure (BP), and a certain concentration of ozone has been associated with decreased BP [9]. There is an association between $\mathrm{PM}_{2.5}$ and inflammation [10]. $\mathrm{PM}_{2.5}$ can also increase the incidence of various respiratory and circulatory diseases $[11,12]$. Even low air pollution concentrations can increase the risk of emergency department visits [13]. One study in an area with a low level of air pollution found that interquartile range (IQR) increases in $\mathrm{PM}_{2.5}, \mathrm{PM}_{10}, \mathrm{NO}_{2}$ and $\mathrm{O}_{3}$ were related to increases in outpatient visits for respiratory conditions [5]. A study that lasted approximately 7 years and considered over 4 million emergency department visits in 31 hospitals showed an association between cardiovascular disease and ambient pollutant levels [14]. Another study conducted over 17 years in Canada reported that ozone is highly associated with circulatory hospitalizations [15]. Some studies have suggested that low-level PM exposure could cause an increased excess risk (ER) of circulatory outpatient visits $[11,16]$. Overall, even if the air quality is good in some regions, the effects of air pollution cannot be ignored.

Similar studies may obtain different outcomes because of differences in pollution concentrations and components and different population age structures and sensitivities among different regions [3]. In particular, regarding the concentration of air pollutants, the association between air pollution and health effects in areas with poor air quality was lower than that in areas with good air quality [2, 17]. Describing the effects of air pollutants via comparisons with analyses of data from other regions is inappropriate; thus, research on the association between air pollutants and outpatient visits is necessary to understand the effects of local air pollution.

Modeling is particularly important in such studies. A single air pollutant model is not sufficient, and comprehensive air pollutant models that consider synergistic effects are essential for studying the association between air pollutants and outpatient visits [18]. We conducted this study to analyze the associations between air pollutants and outpatient visits in Fuzhou using a comprehensive air pollutant model that considers the synergistic effects of different air pollutants, and a total single air pollutant model, a seasonal model (examining the cold season and warm season) and a double pollutant model were constructed.

\section{Methods \\ Data collection}

Our daily air pollution monitoring data were based on 3-year data collection from 1 January 2016 to 31 December 2018 from seven air pollution monitoring stations of the Fuzhou Environmental Monitoring Center Station, and daily meteorological monitoring data were collected through daily monitoring by the Fuzhou Meteorological Bureau, which is part of the nationwide network of monitoring stations and strictly implements relevant national technical requirements. The indicators of air pollution included nitrogen dioxide $\left(\mathrm{NO}_{2}\right)$, daily maximum 8-h mean ozone $\left(\mathrm{O}_{3}-8 \mathrm{~h}\right), \mathrm{PM}_{10}$ and $\mathrm{PM}_{2.5}$. The meteorological indicators included air pressure (AP), relative humidity $(\mathrm{RH})$ and temperature $(\mathrm{T})$. Values of $\mathrm{O}_{3}-8 \mathrm{~h}$, $\mathrm{PM}_{10}$ and $\mathrm{PM}_{2.5}$ were evaluated based on WHO air quality standards $\left(100,50\right.$ and $25 \mu \mathrm{g} / \mathrm{m}^{3}$, respectively), 
and $\mathrm{NO}_{2}$ was evaluated based on the China class I air quality standard $\left(80 \mu \mathrm{g} / \mathrm{m}^{3}\right)$. The daily outpatient visits of Jianxin Hospital and Kongjun Hospital were collected by the Fuzhou Center for Disease Control and Prevention, which has been part of the Fuzhou health monitoring network for 3 consecutive years and was subject to strict quality control according to requirements. We identified diseases according to their International Classification of Diseases, 10th edition (ICD-10) codes (J00J99 for respiratory diseases and I00-199 for circulatory diseases). Among the J00-J99 codes, J00-J06 and J30-J39 represent upper respiratory diseases and J20-J22, J40$\mathrm{J} 47$, and J85-J86 represent lower respiratory diseases.

In the analysis of the association between outpatient visits and air pollutants, there were meteorological factors and natural fluctuations in daily events over the course of a week that we needed to account for. We only collected the total number of outpatient visits that was not contain any individual or patient data. Ethics approval and consent to participate were unnecessary for the present study in accordance with the IRB of Fuzhou Center for Disease Control and Prevention.

\section{Statistical analysis}

In this study, a generalized linear model (GLM) was used to analyze the association between outpatient visits and the studied air pollutants. The GLM with a timeseries regression analysis was based on a Poisson distribution. We introduced meteorological parameters, including $\mathrm{T}\left({ }^{\circ} \mathrm{C}\right)$ and $\mathrm{RH}(\%)$. Because the relationship between meteorology and health is generally nonlinear, we used a natural smoothing spline function to control for this nonlinear hybrid effect. We used 3 degrees of freedom for $\mathrm{T}$ and $\mathrm{RH}[7,18,19]$. The natural spline (ns) function of date was also used in the GLM to address nonlinear trends, sequence correlations and the number of events per day on the time axis. The day of the week (DOW) was considered in this model to control for the natural fluctuation trends over a week. The degrees of freedom (df) for date were $7 \mathrm{df}$ per year [20, $21]$. The model is as follows [22, 23]:

$$
\begin{aligned}
\log E(Y t) & =\beta \mathrm{Zt}+\mathrm{ns}(\text { time }, 7 * 3)+D O W \\
& +n s(X t, 3)+\text { intercept }
\end{aligned}
$$

where $\mathrm{E}(\mathrm{Yt})$ is the expected value of the number of outpatient visits on day $\mathrm{t}$; $\mathrm{Zt}$ is the pollutant concentration on day $t ; \beta$ is the exposure-response coefficient; ns () is the natural smoothing spline function; $\mathrm{df}$ is the degrees of freedom; time is the calendar time variation; DOW is the weekly variation; and $\mathrm{Xt}$ is the meteorological factor.

The study analyzed the ER of outpatient visits associated with air pollutants and included a total single air pollutant model, seasonal model (cold period and warm season) ozone model (exceeding $100 \mu \mathrm{g} / \mathrm{m}^{3}$ of ozone), and double pollutant model. The double air pollutant model considered data from lag0. The seasonal model was divided into a cool period and warm period according to the monthly mean $T$. The months in which the monthly mean $\mathrm{T}$ exceeded $20^{\circ} \mathrm{C}$ were considered the warm period (April-October). Otherwise, the months were considered the cool period (November-March of the following year). The ozone model exceeding $100 \mu \mathrm{g} / \mathrm{m}^{3}$ did not introduce the ns function of date and DOW because of discontinuity. The model is as follows:

$$
\log E(Y t)=\beta Z t+n s(X t, 3)+\text { intercept }
$$

where $\mathrm{E}(\mathrm{Yt})$ is the expected value of the number of outpatient visits on day $\mathrm{t} ; \mathrm{Zt}$ is the pollutant concentration on day $t ; \beta$ is the exposure-response coefficient; ns () is the natural smoothing spline function; and $\mathrm{df}$ is the degrees of freedom. We also conducted a Wilcoxon paired test to identify the significance of the relationship in different seasons. The mgcv package of the $\mathrm{R}$ 3.5.1 statistical software platform was used for calculating and painting.

\section{Results}

\section{Descriptive analyses}

Table 1 shows that during the study, the mean pollutant concentrations were $27.38 \mu \mathrm{g} / \mathrm{m}^{3}$ for $\mathrm{NO}_{2}, 89.60 \mu \mathrm{g} / \mathrm{m}^{3}$ for daily $\mathrm{O}_{3}-8 \mathrm{~h}, 26.07 \mu \mathrm{g} / \mathrm{m}^{3}$ for $\mathrm{PM}_{2.5}$, and $49.68 \mu \mathrm{g} / \mathrm{m}^{3}$ for $\mathrm{PM}_{10}$. During the study, the $\mathrm{O}_{3}-8 \mathrm{~h}$ concentration exceeded $100 \mu \mathrm{g} / \mathrm{m}^{3}$ for a total of 390 days, the $\mathrm{NO}_{2}$ concentration exceeded $80 \mu \mathrm{g} / \mathrm{m}^{3}$ for a total of 0 days, the $\mathrm{PM}_{2.5}$ concentration exceeded $25 \mu \mathrm{g} / \mathrm{m}^{3}$ for a total of 509 days, and the $\mathrm{PM}_{10}$ concentration exceeded $50 \mu \mathrm{g} /$ $\mathrm{m}^{3}$ for a total of 478 days. The mean daily average $\mathrm{T}, \mathrm{RH}$ and AP were $21.54{ }^{\circ} \mathrm{C}, 72 \%$ and $1010 \mathrm{hpa}$, respectively.

\section{Association between air pollution and meteorological factors}

Figure 1 shows that except for $\mathrm{T}$ and $\mathrm{PM}_{10}$, meteorological factors were significantly correlated with air pollutants. $\mathrm{RH}$ was positively correlated with $\mathrm{NO}_{2}$ and negatively correlated with $\mathrm{O}_{3}-8 \mathrm{~h}, \mathrm{PM}_{2.5}$ and $\mathrm{PM}_{10}$. T was positively correlated with $\mathrm{O}_{3}-8 \mathrm{~h}$ and negatively correlated with $\mathrm{NO}_{2}, \mathrm{PM}_{2.5}$ and $\mathrm{PM}_{10}$. AP was positively correlated with $\mathrm{PM}_{10}, \mathrm{NO}_{2}$ and $\mathrm{PM}_{2.5}$ and negatively correlated with $\mathrm{O}_{3}-8$ h.

\section{Time series distribution of air pollutants and outpatient visits}

Figure 2a shows that $\mathrm{NO}_{2}, \mathrm{PM}_{10}$ and $\mathrm{PM}_{2.5}$ had higher concentrations during the cold season than during the 
Table 1 Statistical summary of daily air pollutants, meteorological factors and outpatient visits in Fujian, China, 2016-2018

\begin{tabular}{|c|c|c|c|c|c|c|}
\hline \multirow[t]{2}{*}{ Variable } & \multirow[t]{2}{*}{ Mean \pm SD } & \multirow[t]{2}{*}{ Minimum } & \multicolumn{3}{|c|}{ Percentile } & \multirow[t]{2}{*}{ Maximun } \\
\hline & & & 25 th & 50th & 75th & \\
\hline \multicolumn{7}{|l|}{ Total } \\
\hline Respiratory disease & $82 \pm 32$ & 1 & 60 & 83 & 104 & 180 \\
\hline Upper respiratory disease & $49 \pm 20$ & 0 & 35 & 49 & 63 & 113 \\
\hline Lower respiratory disease & $16 \pm 8$ & 0 & 10 & 16 & 22 & 47 \\
\hline Circulatory disease & $174 \pm 83$ & 0 & 105 & 191 & 231 & 382 \\
\hline $\mathrm{NO}_{2}\left(\mu \mathrm{g} / \mathrm{m}^{3}\right)$ & $27.38 \pm 11.18$ & 3.83 & 19.55 & 25.14 & 33.14 & 79.57 \\
\hline $\mathrm{O}_{3}-8 \mathrm{~h}\left(\mu \mathrm{g} / \mathrm{m}^{3}\right)$ & $89.60 \pm 33.94$ & 16.71 & 64.02 & 87.36 & 112.00 & 208.43 \\
\hline $\mathrm{PM}_{2.5}\left(\mu \mathrm{g} / \mathrm{m}^{3}\right)$ & $26.07 \pm 13.14$ & 2.43 & 16.57 & 23.86 & 32.71 & 83.57 \\
\hline $\mathrm{PM}_{10}\left(\mu \mathrm{g} / \mathrm{m}^{3}\right)$ & $49.68 \pm 22.62$ & 7.43 & 33.33 & 46.49 & 63.89 & 167.57 \\
\hline Temperature $\left({ }^{\circ} \mathrm{C}\right)$ & $21.54 \pm 7.08$ & 2.60 & 15.60 & 22.00 & 28.00 & 32.80 \\
\hline Relative humidity (\%) & $72 \pm 11$ & 33 & 65 & 72 & 79 & 99 \\
\hline Air pressure (hpa) & $1010 \pm 8$ & 983 & 1003 & 1009 & 1016 & 1034 \\
\hline \multicolumn{7}{|l|}{ Cold season } \\
\hline Respiratory disease & $91 \pm 34$ & 1 & 70 & 96 & 114 & 166 \\
\hline Upper respiratory disease & $55 \pm 22$ & 0 & 43 & 56 & 70 & 106 \\
\hline Under respiratory disease & $18 \pm 9$ & 0 & 12 & 19 & 25 & 46 \\
\hline Circulatory disease & $175 \pm 84$ & 0 & 108 & 195 & 236 & 367 \\
\hline $\mathrm{NO}_{2}\left(\mu \mathrm{g} / \mathrm{m}^{3}\right)$ & $33.11 \pm 11.55$ & 10.43 & 24.57 & 31.72 & 41.34 & 79.57 \\
\hline $\mathrm{O}_{3}-8 \mathrm{~h}\left(\mu \mathrm{g} / \mathrm{m}^{3}\right)$ & $74.21 \pm 26.59$ & 16.71 & 53.66 & 73.72 & 92.97 & 168.14 \\
\hline $\mathrm{PM}_{2.5}\left(\mu \mathrm{g} / \mathrm{m}^{3}\right)$ & $30.42 \pm 14.44$ & 2.43 & 19.86 & 28.14 & 38.50 & 82.14 \\
\hline $\mathrm{PM}_{10}\left(\mu \mathrm{g} / \mathrm{m}^{3}\right)$ & $52.28 \pm 23.48$ & 7.43 & 33.72 & 50.79 & 68.54 & 134.14 \\
\hline Temperature $\left({ }^{\circ} \mathrm{C}\right)$ & $14.66 \pm 4.11$ & 2.60 & 11.60 & 14.30 & 14.30 & 24.70 \\
\hline Relative humidity (\%) & $72 \pm 12$ & 33 & 63 & 73 & 80 & 98 \\
\hline Air pressure (hpa) & $1017 \pm 6$ & 1001 & 1013 & 1016 & 1021 & 1034 \\
\hline \multicolumn{7}{|l|}{ Warm season } \\
\hline Respiratory disease & $76 \pm 29$ & 11 & 56 & 77 & 95 & 180 \\
\hline Upper respiratory disease & $45 \pm 18$ & 5 & 33 & 44 & 56 & 113 \\
\hline Under respiratory disease & $15 \pm 8$ & 0 & 10 & 15 & 20 & 47 \\
\hline Circulatory disease & $173 \pm 81$ & 13 & 103 & 189 & 229 & 382 \\
\hline $\mathrm{NO}_{2}\left(\mu \mathrm{g} / \mathrm{m}^{3}\right)$ & $23.32 \pm 8.92$ & 3.83 & 17.74 & 22.00 & 27.20 & 73.29 \\
\hline $\mathrm{O}_{3}-8 \mathrm{~h}\left(\mu \mathrm{g} / \mathrm{m}^{3}\right)$ & $100.48 \pm 34.39$ & 30.00 & 75.04 & 99.24 & 124.14 & 208.43 \\
\hline $\mathrm{PM}_{2.5}\left(\mu \mathrm{g} / \mathrm{m}^{3}\right)$ & $22.99 \pm 11.17$ & 4.86 & 15.14 & 21.00 & 28.86 & 83.57 \\
\hline $\mathrm{PM}_{10}\left(\mu \mathrm{g} / \mathrm{m}^{3}\right)$ & $47.84 \pm 21.82$ & 10.29 & 33.04 & 44.14 & 60.03 & 167.57 \\
\hline Temperature $\left({ }^{\circ} \mathrm{C}\right)$ & $26 \pm 4$ & 14.50 & 23.53 & 27.10 & 27.10 & 32.80 \\
\hline Relative humidity (\%) & $72 \pm 11$ & 41 & 65 & 72 & 79 & 99 \\
\hline Air pressure (hpa) & $1005 \pm 6$ & 983 & 1001 & 1004 & 1008 & 1022 \\
\hline \multicolumn{7}{|c|}{$\mathrm{O}_{3}$ concentrations exceeding $100 \mu \mathrm{g} / \mathrm{m}^{3}$} \\
\hline Respiratory disease & $82 \pm 30$ & 12 & 61 & 84 & 102 & 163 \\
\hline Upper respiratory disease & $49 \pm 19$ & 7 & 36 & 47 & 62 & 103 \\
\hline Lower respiratory disease & $17 \pm 8$ & 0 & 11 & 17 & 23 & 47 \\
\hline Circulatory disease & $181 \pm 81$ & 18 & 115.5 & 194.5 & 238.75 & 382 \\
\hline $\mathrm{NO}_{2}\left(\mu \mathrm{g} / \mathrm{m}^{3}\right)$ & $25.16 \pm 7.56$ & 10.14 & 20.14 & 23.745 & 28.2825 & 56.14 \\
\hline $\mathrm{O}_{3}-8 \mathrm{~h}\left(\mu \mathrm{g} / \mathrm{m}^{3}\right)$ & $126.36 \pm 20.89$ & 100.14 & 109.86 & 121.71 & 136.66 & 208.43 \\
\hline
\end{tabular}


Table 1 Statistical summary of daily air pollutants, meteorological factors and outpatient visits in Fujian, China, 2016-2018 (Continued)

\begin{tabular}{lllllll}
\hline Variable & Mean $\pm \mathrm{SD}$ & Minimum & & \multicolumn{2}{c}{ Percentile } & Maximum \\
\cline { 5 - 6 } & & & 25 th & 50th & 75th \\
\hline $\mathrm{PM}_{2.5}\left(\mu \mathrm{g} / \mathrm{m}^{3}\right)$ & $29.81 \pm 10.97$ & 6.43 & 15.74 & 27.86 & 35.57 & 70.43 \\
$\mathrm{PM}_{10}\left(\mu \mathrm{g} / \mathrm{m}^{3}\right)$ & $59.81 \pm 19.55$ & 8.5 & 45.895 & 57.43 & 70.86 & 164.14 \\
Temperature $\left({ }^{\circ} \mathrm{C}\right)$ & $24.36 \pm 6.46$ & 41 & 19.75 & 26 & 26 & 32.8 \\
Relative humidity (\%) & $66 \pm 9$ & 992 & 60 & 66 & 72 & 96 \\
Air pressure (hpa) & $1007 \pm 7$ & & 1002 & 1006 & 1013 & 1031 \\
\hline
\end{tabular}

warm season while $\mathrm{O}_{3}-8 \mathrm{~h}$ had a higher concentration during the warm season than the cold season. Figure $2 \mathrm{~b}$ shows that respiratory diseases, including upper and lower respiratory diseases, resulted in more outpatient visits during the cold season than during the warm season.

\section{Association between air pollutants and outpatient visits}

In Fig. 3a, the single air pollutant model shows that $\mathrm{NO}_{2}$ had a significant effect on the ER of total respiratory, lower respiratory, upper respiratory and circulatory diseases. Moreover, Table S1 also provides the single-day lag effect that was most obvious at lag0 and increased by 5.11\% (95\% CI: 3.31-6.95\%) for total respiratory visits, 6.04\% (95\% CI: $3.91-8.21 \%$ ) for upper respiratory visits,
3.23\% (95\% CI: $0.46-6.08 \%$ ) for lower respiratory visits, and $4.75 \%(95 \% \mathrm{CI}: 6.81-2.73 \%)$ for circulatory outpatient visits. The cumulative lag effect was the most obvious at lag0-5 and increased by $9.43 \%$ (95\% CI: 6.31-12.65\%) for total respiratory disease, 10.96\% (95\% CI: $7.22-14.84 \%)$ for upper respiratory disease, $7.69 \%$ (95\% CI: 2.96-12.64\%) for lower respiratory disease, and 8.14\% (95\% CI: 4.74-11.65\%) for circulatory diseases.

As shown in Fig. 3b and Table S2, after adjusting for the three other air pollutants, the ER of $\mathrm{O}_{3}-8 \mathrm{~h}$ did not obviously change. After adjusting for $\mathrm{PM}_{2.5}$ and $\mathrm{PM}_{10}$, $\mathrm{NO}_{2}$ increased greatly. Because of the possible collinearity of $\mathrm{PM}_{10}$ and $\mathrm{PM}_{2.5}$, we did not introduce them into our model, although after adjusting for $\mathrm{NO}_{2}$, the ERs of $\mathrm{PM}_{10}$ and $\mathrm{PM}_{2.5}$ decreased.

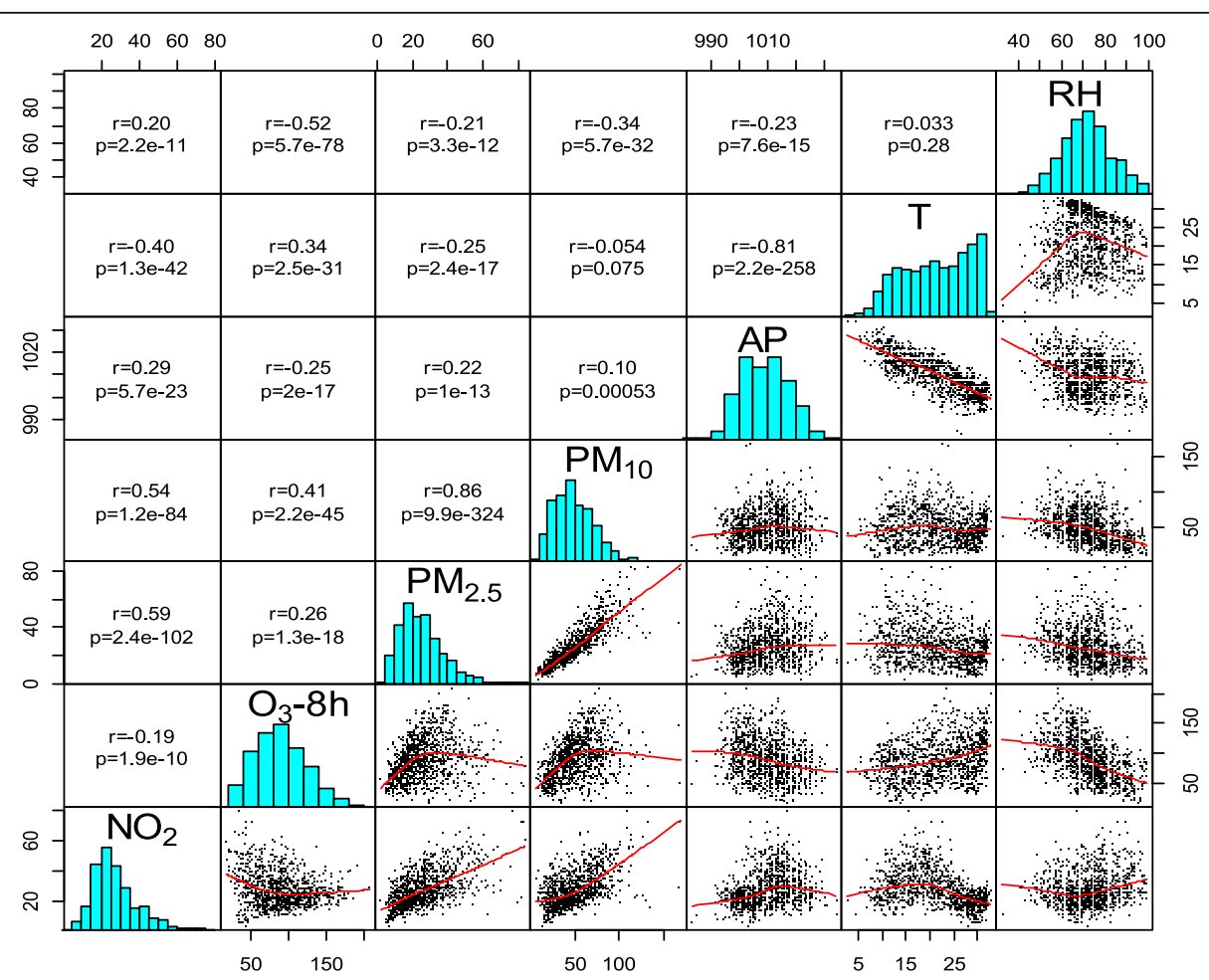

Fig. 1 Spearman correlations between air pollutants and meteorological factors from 2016 to 2018. RH, relative humidity; T, temperature; AP, air pressure; $\mathrm{PM}_{10}$, particulate matter with an aerodynamic diameter less than $10 \mu^{-3} ; \mathrm{PM}_{2.5}$, particulate matter with an aerodynamic diameter less than $2.5 \mathrm{\mu m}^{-3} ; \mathrm{O}_{3}-8 \mathrm{~h}$, daily maximum 8-h mean ozone; $\mathrm{NO}_{2}$, nitrogen dioxide 


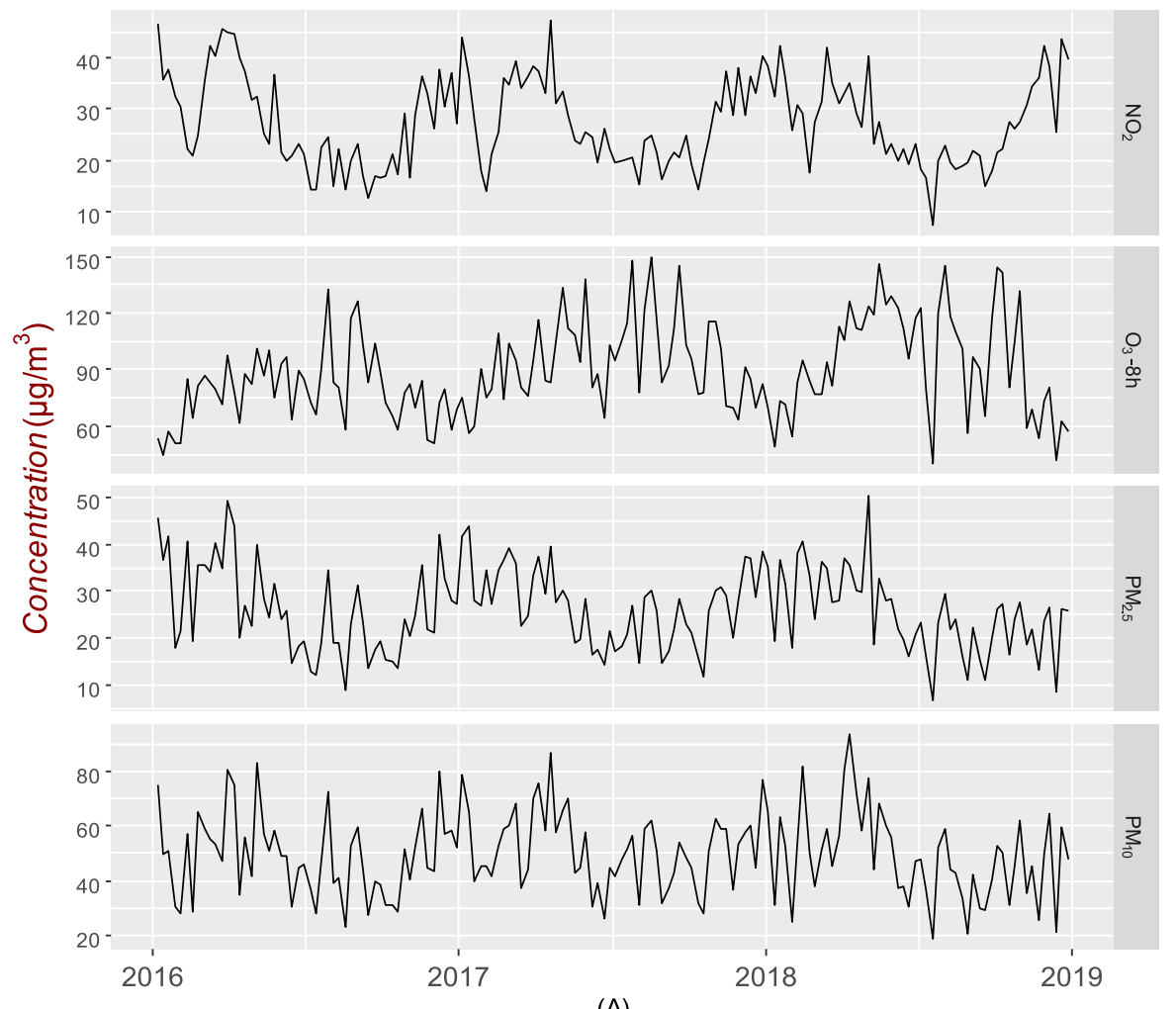

(A)

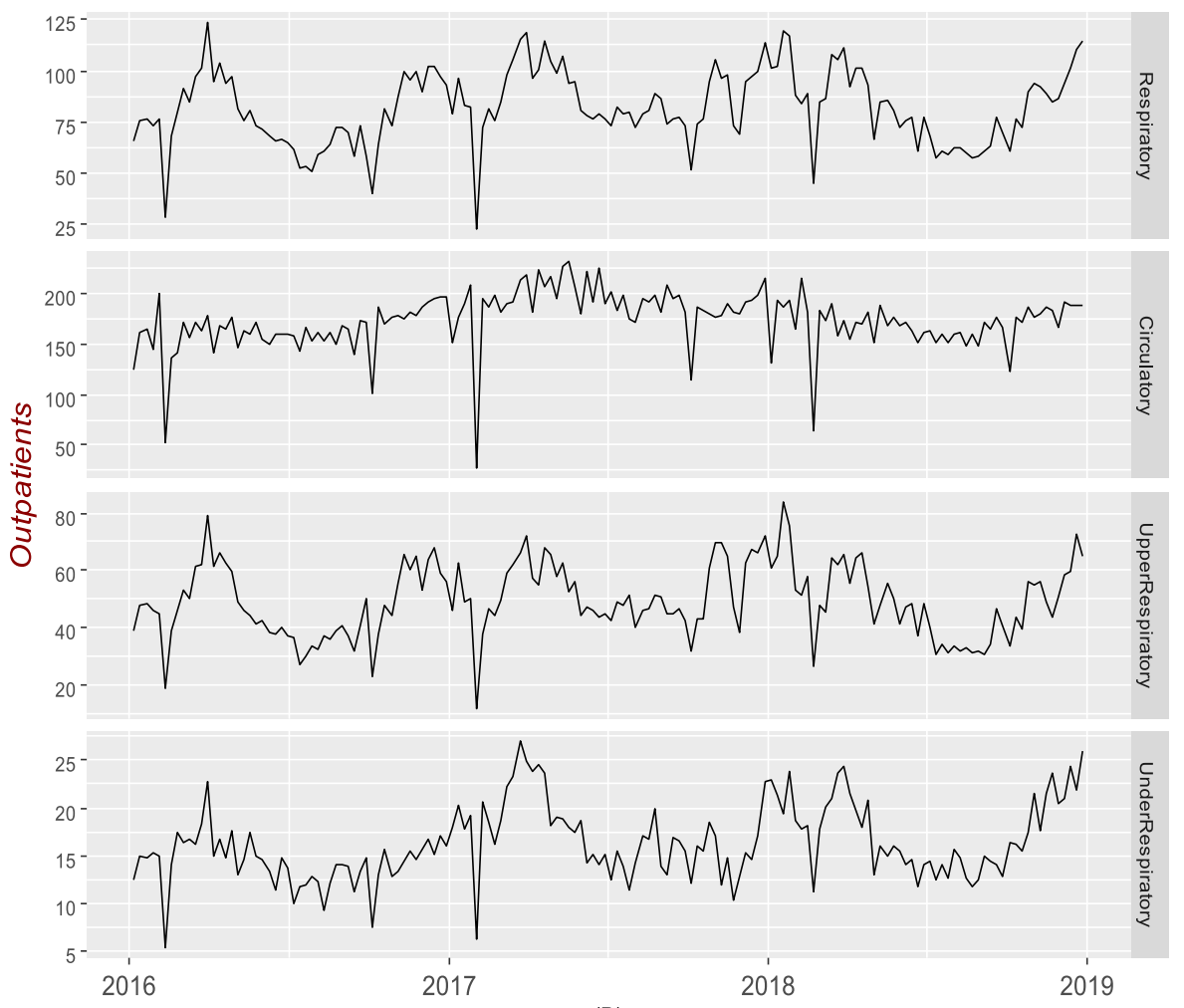

(B)

Fig. 2 Time series distribution of air pollutants and outpatient visits. Time series graphs of weekly air pollutants (a) and outpatient visits (b) for total respiratory, lower respiratory, upper respiratory and circulatory diseases 


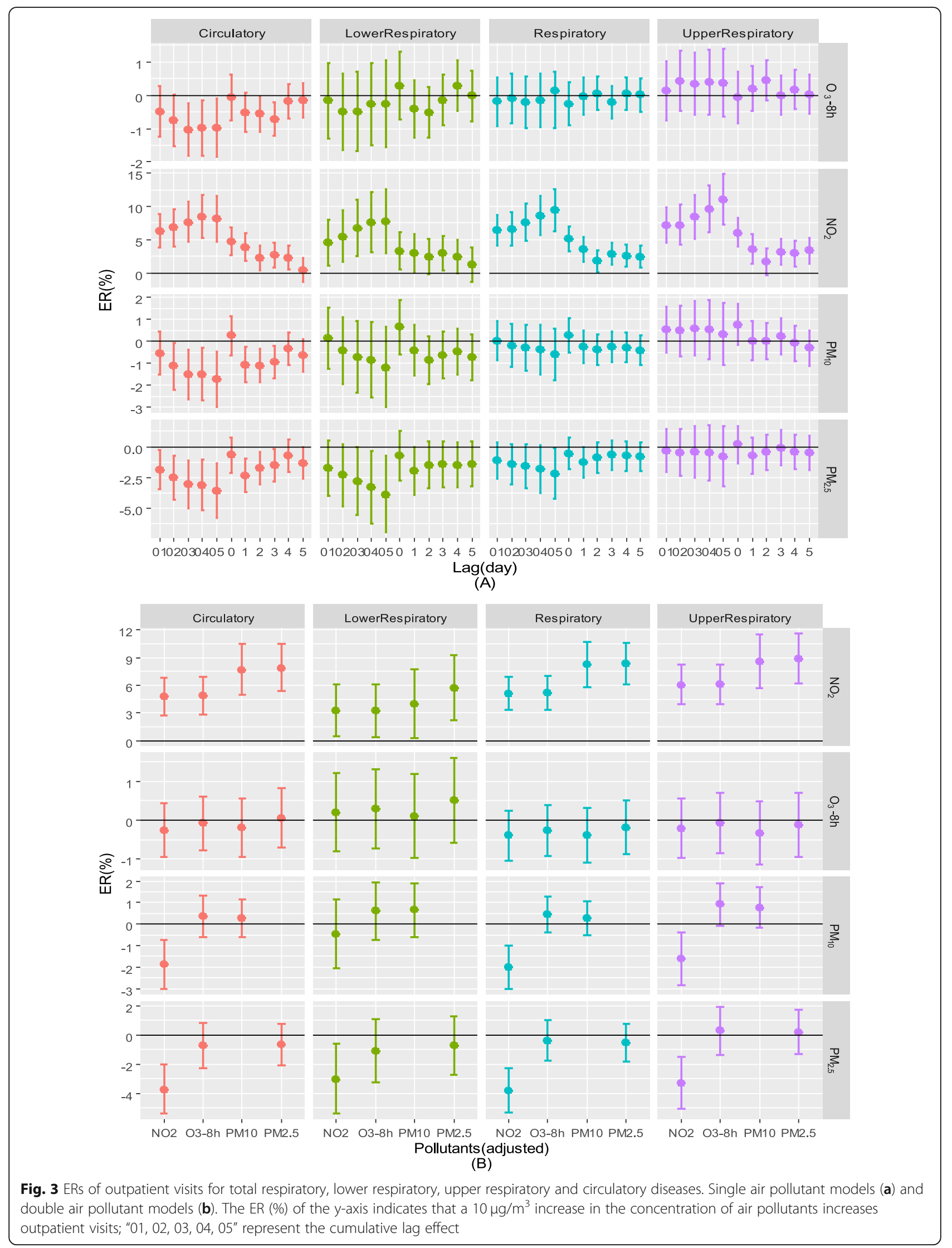



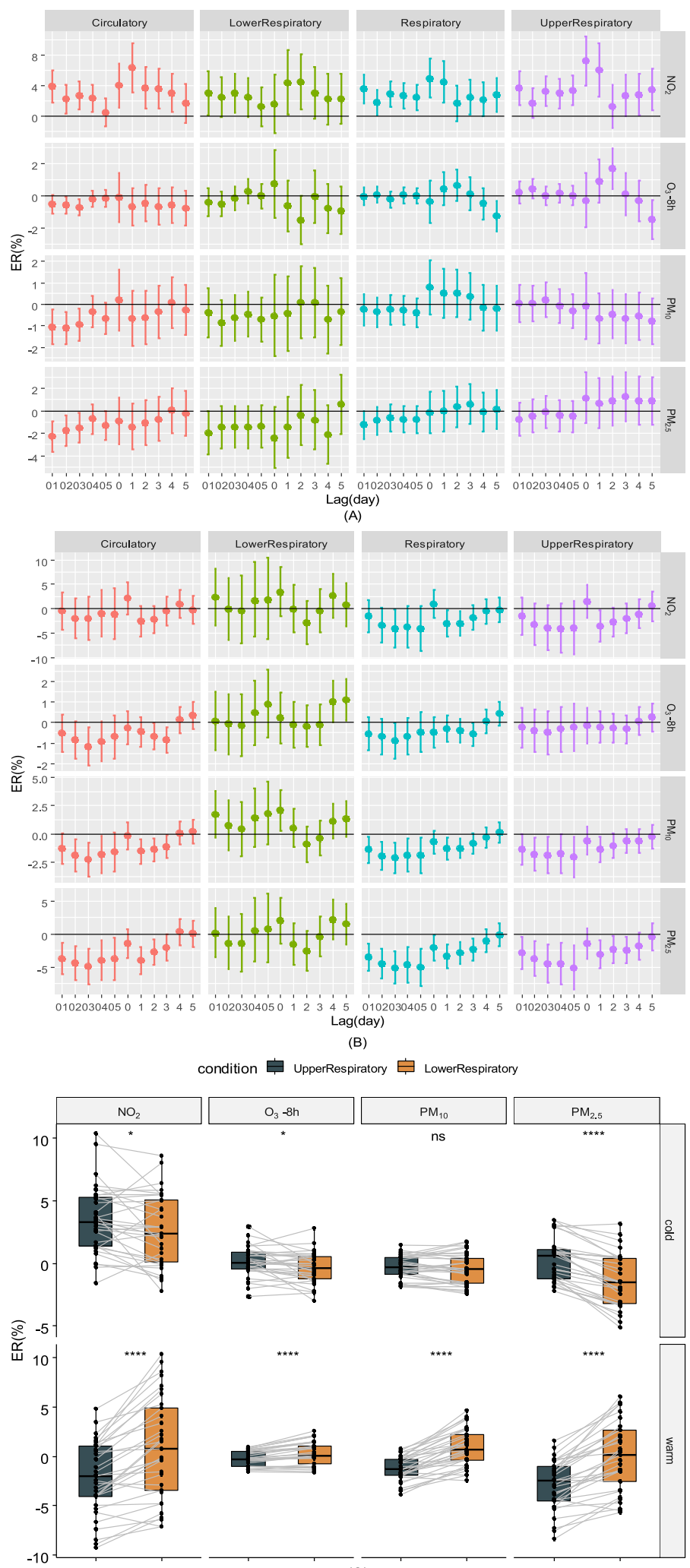

(C)

Fig. 4 ERs of outpatient visits for total respiratory, lower respiratory, upper respiratory and circulatory diseases in the different periods. Cold period (a), warm period (b) and the Wilcoxon paired test of ERs between the upper respiratory and lower respiratory periods in different periods $(\mathbf{c})$. $(p>$ 0.05: 'ns'; $0.01<p<0.05:{ }^{*^{* \prime} ;} ; 0.001<p<0.01::^{* * *^{\prime}} ; 0.0001<p<0.001:^{: * * *} ; p<0.0001:^{* * * * * \prime}$ ) 
Figure 4a shows the association between the different air pollutants and outpatient visits during the cold seasons. During the cold season, $\mathrm{NO}_{2}$ appeared to have an obvious effect, although its effect was less than that during the warm season. Eight-hour $\mathrm{O}_{3}$ had a significant impact on outpatient visits for upper respiratory diseases at lag2 during the cold season, and the ER was $1.68 \%$ (2.94-0.44\%), as also shown in Table S3.

Figure $4 \mathrm{~b}$ shows the association between the different air pollutants and outpatient visits during the warm season. During this period, $\mathrm{NO}_{2}$ had no significant association with outpatient visits. Eight-hour $\mathrm{O}_{3}$ had a significant effect on outpatient visits for lower respiratory conditions at lag4 $(1.02,95 \% \mathrm{CI}: 0.032-$ $2.02 \%)$ and lag5 (1.10, 95\% CI: $0.11-2.11 \%)$, and $\mathrm{PM}_{10}$ had a significant impact on outpatient visits for upper respiratory conditions at lag0 (2.05\%, CI: $0.27-3.86 \%)$ (see Additional file 1: Table S4). Figure 4c shows the results of the Wilcoxon paired test for lower and upper respiratory diseases in different seasons that was used to test for significance. We calculated the circulatory effects of air pollutants when the daily $\mathrm{T}$ was higher and lower than $30^{\circ} \mathrm{C}$ during the warm season, and we found that heat posed higher risks of circulatory disease, although the difference was not significant (see Additional file 1: Fig. S1).

Figure 5 and Table S5 show that when the concentration of $\mathrm{O}_{3}-8 \mathrm{~h}$ was higher than $100 \mu \mathrm{g} / \mathrm{L}$, there was a positive effect on circulatory [lag5, ER $(95 \% \mathrm{CI}): 2.83 \%$ (0.65-5.06\%)], respiratory [lag5, ER $(95 \%$ CI): $2.47 \%$ (0.85-4.11\%)] and upper respiratory [lag5, ER (95\% CI): $3.06 \%(1.38-4.77 \%)]$ outpatient visits.

\section{Discussion}

In this study, $\mathrm{NO}_{2}$ presented a more obvious effect than the other three air pollutants in Fuzhou. We explored the relationship between air pollutants and outpatient visits for different diseases and in different seasons. During the cold season, there were more outpatient visits for respiratory, upper respiratory and circulatory diseases

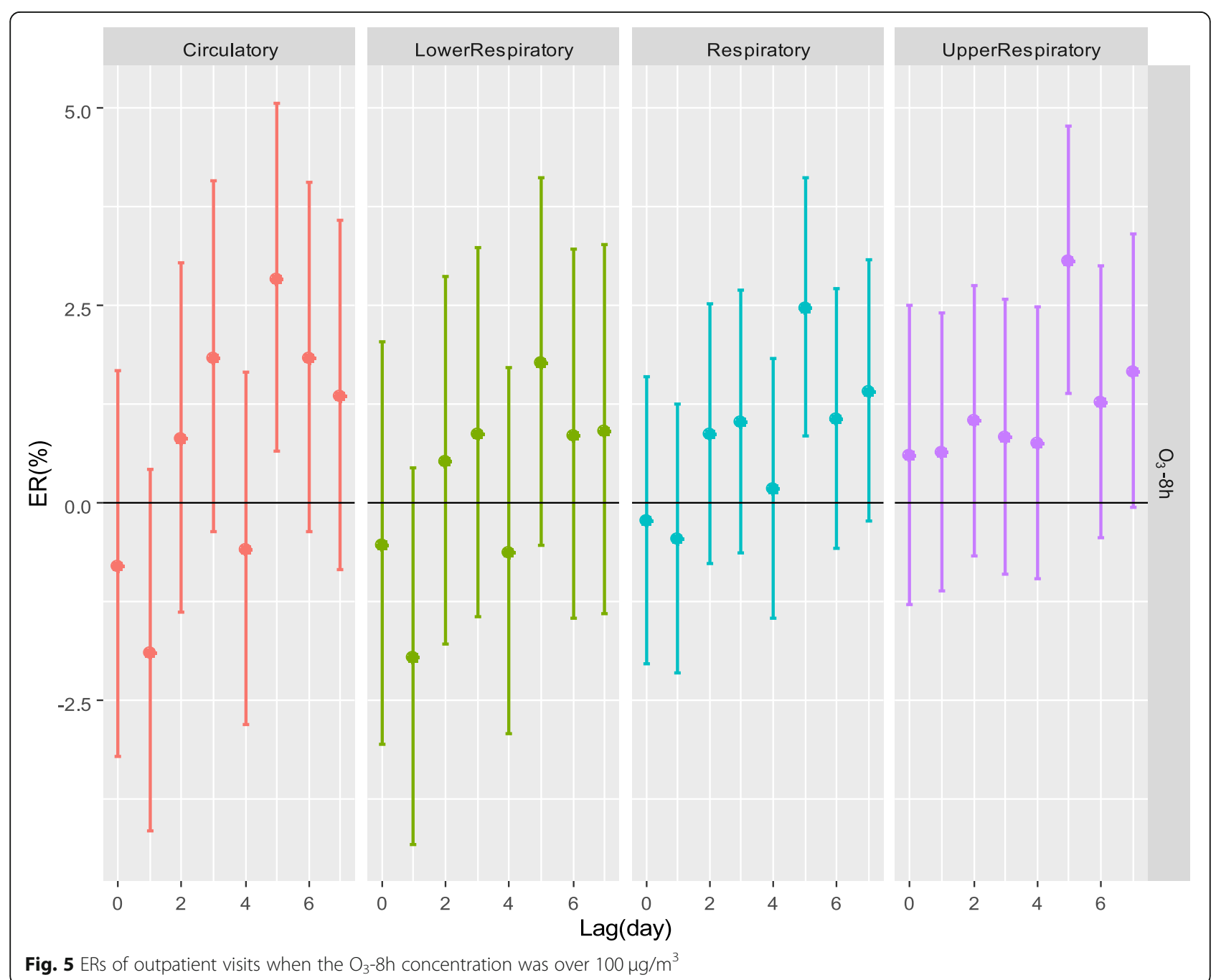


in association with the effects of $\mathrm{O}_{3}-8 \mathrm{~h}, \mathrm{PM}_{2.5}$ and $\mathrm{PM}_{10}$ than during the warm season; however, during the warm season, there were more outpatient visits for lower respiratory diseases in association with those three air pollutants than there were during the cold season. In the double pollutant model, after adjusting for $\mathrm{NO}_{2}$, the effects of the other three air pollutants decreased. After adjusting for $\mathrm{PM}_{2.5}, \mathrm{PM}_{10}$ showed a significant effect. After adjusting for the other three air pollutants, the ER of $\mathrm{O}_{3}-8$ h changed only slightly. Different air pollutants presented different effects because of different conditions.

Our study showed the association between meteorological factors and the air pollutants $\mathrm{NO}_{2}, \mathrm{O}_{3}-8 \mathrm{~h}, \mathrm{PM}_{10}$ and $\mathrm{PM}_{2.5}$. We found that the action of $\mathrm{AP}, \mathrm{RH}$ and $\mathrm{T}$ caused high concentrations of air pollutants. Other studies have shown that meteorological factors have an effect on the concentrations of air pollutants, which is similar to the findings of our study [24, 25]. RH is known to increase haze, possibly because $\mathrm{RH}$ is positively correlated with $\mathrm{NO}_{2}$, which converts from the gas phase of $\mathrm{NO}_{\mathrm{x}}$ to the particulate phase under relatively low-visibility conditions [26]. We did not find a positive association between PM and RH in the Spearman correlation model, although in the contour plot, the correlation between $\mathrm{RH}$ and $\mathrm{PM}_{10}$ and $\mathrm{PM}_{2.5}$ first increased and then decreased at a certain AP and T. The joint action of meteorological factors had seemingly obvious effects on PM. $\mathrm{O}_{3}$ had a positive association with $\mathrm{T}$ and a negative association with $\mathrm{RH}$ because sunshine might be the main promoter of $\mathrm{O}_{3}$ because $\mathrm{O}_{3}$ is enhanced by photochemical factors and $\mathrm{RH}$ can affect sunshine duration [27]. Meteorological factors can influence air pollution, thereby impacting health. Therefore, meteorological factors were introduced into the GLM. The time series diagram shows that during the cold season, all the air pollutants except ozone had higher concentrations than during the warm season. This discrepancy is due to the negative association between $\mathrm{T}$ and air pollutants and the positive association between AP and air pollutants other than ozone. In addition to meteorological factors, emissions also increase pollutant concentrations [28]. During the cold season in Fuzhou, heating is provided by lighting fires rather than using coal, which leads to increased PM emissions. The time series diagram also shows that there were more outpatient visits for respiratory diseases, including upper and lower respiratory diseases, during the cold season than the warm season, which may be different from the findings for other regions; for example, the spring dust storm season in Lanzhou may increase emergency room visits for respiratory diseases [29].

The GLM reflected different aspects, including the total situation, different seasons and double air pollutants. Because of the significant effects of the different air pollutants, we conducted a comprehensive study to evaluate the ERs of $\mathrm{NO}_{2}, \mathrm{O}_{3}, \mathrm{PM}_{2.5}$ and $\mathrm{PM}_{10}$ [30, 31]. In the overall model, we found that $\mathrm{NO}_{2}$ had a more obvious effect than the other three air pollutants on the ER of outpatient visits, especially considering the cumulative lag effect. Some studies also found that $\mathrm{NO}_{2}$ was strongly associated with hospital admissions for both respiratory and cardiovascular diseases [32, 33]. In China, the Sixth National Population Census showed that coastal areas had become old-age societies and a systematic review and meta-analysis reported that the effect of $\mathrm{NO}_{2}$ exhibited regional differences because of differences in the proportions of elderly people with increased susceptibility to $\mathrm{NO}_{2}$, which may be the cause of the high ER associated with $\mathrm{NO}_{2}$ [34]. Even when air quality is not poor, the elderly may still be susceptible to air pollutants.

However, when we examined the results according to season, the effect of $\mathrm{NO}_{2}$ was less significant than that of the total situation. Moreover, the $\mathrm{ER}$ of $\mathrm{NO}_{2}$ was lower during the warm season than the cold season and lost all significance during the warm season. In addition to $\mathrm{T}$, the concentrations of air pollutants differed between the cold season and warm season. During the cold season, the concentration of $\mathrm{NO}_{2}$ was $33.11 \mu \mathrm{g} / \mathrm{m}^{3}$, while during the warm season, it was $23.32 \mu \mathrm{g} / \mathrm{m}^{3}$. There is a dose-dependent relationship between pulmonary injuries and ambient $\mathrm{NO}_{2}$ [35], although for circulatory injuries, such research is lacking. Interestingly, $\mathrm{NO}_{2}, \mathrm{O}_{3}, \mathrm{PM}_{2.5}$ and $\mathrm{PM}_{10}$ had similar results in terms of their influence on outpatient visits for upper and lower respiratory diseases. Generally, $\mathrm{PM}_{10}$ has a greater impact on the upper respiratory tract than the lower respiratory tract, while $\mathrm{PM}_{2.5}$ and $\mathrm{O}_{3}$ exhibit the opposite effect. During the cold season, the increase in outpatient visits for upper respiratory disease was greater than that during the warm season, while the opposite results were observed for lower respiratory disease-related visits except in the case of $\mathrm{NO}_{2}$. Nitrogen dioxide, ozone and $\mathrm{PM}_{2.5}$ caused more ERs for upper respiratory-related outpatient visits than for lower respiratory-related outpatient visits during the cold period, whereas nitrogen dioxide, ozone, $\mathrm{PM}_{2.5}$ and $\mathrm{PM}_{10}$ caused more ERs for lower respiratoryrelated outpatient visits during the warm season. $\mathrm{T}$ and AP were $14.66^{\circ} \mathrm{C}$ and $1016.65 \mathrm{hPa}$ during the cold season, respectively, and $26.40^{\circ} \mathrm{C}$ and $1004.66 \mathrm{hPa}$ during the warm season, respectively. Some studies reported that low $\mathrm{AP}$ and warm $\mathrm{T}$ increased susceptibility to respiratory-related diseases [36, 37]. A study pointed out that a greater diurnal $\mathrm{T}$ range caused more outpatient visits for the common cold [38]. Similarly, greater $\mathrm{T}$ change affects the number of hospital admissions for chronic obstructive pulmonary disease [39]. Fuzhou 
often experiences a high diurnal $\mathrm{T}$ range during cold periods. However, $\mathrm{PM}$ and $\mathrm{O}_{3}$ had greater effects on upper respiratory-related outpatient visits during the cold season and lower respiratory-related outpatient visits during the warm season, which was possibly because the depths of the respiratory tract that pollutants are able to reach are impacted by $\mathrm{T}$ and AP; however, this theory needs further study. Regarding circulatory diseases, in our study, we found that during the cold season, air pollutants increased the number of outpatient visits for circulatory diseases, and previous studies have presented similar outcomes $[33,40]$. However, a study conducted over a 17 -year period in Canada reported that 1-day lagged ozone had a greater association with the three examined circulatory hospitalization causes (ischemic heart disease, other heart disease and cerebrovascular disease) during the warm season than during the cold season [15]. A study in Hong Kong reported that $\mathrm{PM}$ and $\mathrm{NO}_{2}$ increased emergency hospital admissions during the warm season [41]. During our study, increased concentrations of $\mathrm{PM}$ and $\mathrm{NO}_{2}$ were observed during the cold season while an increased concentration of $\mathrm{O}_{3}$ was not. In addition to the increased concentrations of air pollutants, heat waves and other extreme high- $T$ events were more likely to occur on low-T days, which may cause more outpatient visits for circulatory diseases [42]. We found that during the warm season of high Ts $\left(>30^{\circ} \mathrm{C}\right)$, pollutants cause greater damage to the cardiovascular system than when $\mathrm{T}$ is less than $30^{\circ} \mathrm{C}$. Studies have reported that under high- $\mathrm{T}$ conditions, the risk of ozonerelated cardiovascular death increases and PM has a greater impact on the cardiovascular system; thus, $\mathrm{T}$ and pollutants may have a synergistic effect on cardiovascular disease $[18,43]$. However, a study in low-pollution areas found that the effects of $\mathrm{PM}_{2.5}$ were more obvious during the cool season than the warm season [5].

We also conducted analyses of ozone concentrations exceeding $100 \mu \mathrm{g} / \mathrm{m}^{3}$ because ozone pollution is serious. The model with ozone exceeding $100 \mu \mathrm{g} / \mathrm{m}^{3} \mathrm{did}$ not introduce the ns function of date and DOW because of discontinuities. Ozone exceeded $100 \mu \mathrm{g} / \mathrm{m}^{3}$ for a total of 390 days during the study period (total study period, 1096 days) and a total of 315 days during the warm season. The warm season model showed that high ozone levels had a significant effect on respiratory outpatient visits at lag4 and lag5. The time at which the significant effect appeared was the same in the warm period model and the ozone exceeding $100 \mu \mathrm{g} / \mathrm{m}^{3}$ model, although the predominant diseases were different, which may be related to the increased concentration of $\mathrm{O}_{3}$ in the $100 \mu \mathrm{g} / \mathrm{m}^{3}$ ozone model $\left[\mathrm{O}_{3}-8 \mathrm{~h}\right.$ average (standard $\mathrm{O}_{3}-8 \mathrm{~h}$ concentration model): 126.36 $\mu \mathrm{g} / \mathrm{m}^{3}$ vs $\mathrm{O}_{3}-8 \mathrm{~h}$ average (warm season average): $\left.100.48 \mu \mathrm{g} / \mathrm{m}^{3}\right]$.
In the double model, after adjusting for $\mathrm{PM}_{2.5}, \mathrm{NO}_{2}$ and $\mathrm{O}_{3}-8 \mathrm{~h}$ presented increased ERs at lag0. In contrast, after adjusting for $\mathrm{NO}_{2}$, the other three pollutants, especially $\mathrm{PM}\left(\mathrm{PM}_{2.5}\right.$ and $\left.\mathrm{PM}_{10}\right)$, presented decreased ERs. There was a strong correlation between $\mathrm{PM}$ and $\mathrm{NO}_{2}$. The ER of ozone did not fluctuate considerably after adjusting for the three other pollutants. The interaction between PM and $\mathrm{NO}_{2}$ was strong, and the effect of $\mathrm{O}_{3}-8 \mathrm{~h}$ was independent. Previous studies also found a strong correlation between PM and gaseous air pollution except for $\mathrm{O}_{3}$, which did not change much after the other air pollutants were added to the model $[6,18]$. Some studies on mechanics noted that inflammation, oxidative stress, changes in systemic coagulation functioning and reduced cardiac autonomic control occurred after exposure to gaseous air pollutants and PM $[44,45]$, which may trigger respiratory and cardiovascular events as well as high concentrations of air pollutants (except $\mathrm{O}_{3}-8 \mathrm{~h}$ ) during the same period (the cold season). These factors may cause high correlations among air pollutants. Therefore, it is difficult to evaluate the independent effects of $\mathrm{PM}$ or $\mathrm{NO}_{2}$ because of their high correlations [17].

Several limitations affected this study. In coastal areas, ozone pollution is more serious than $\mathrm{PM}$ and $\mathrm{NO}_{2}$ pollution, although in this study, $\mathrm{NO}_{2}$ increased the number of outpatient visits. Eight-hour $\mathrm{O}_{3}$ and $\mathrm{NO}_{2}$ are related to photochemical smog, and they promote one another; thus, they may exhibit joint action. However, we could not find obvious interactions in the double model; therefore, further research is required. $\mathrm{PM}_{2.5}$ increased the outpatient visit risk rate in many studies, even in areas with better air quality than Fuzhou, which may indicate that there are regional differences in the effect of $\mathrm{PM}_{2.5}$ exposure in China [46]. In our study, we did not observe a significant effect of $\mathrm{PM}_{2.5}$. If we stratify the results by different ages and diseases, we may obtain significant outcomes. Overall, our study provided a comprehensive analysis of the association between air pollutants and outpatient visits. In some comprehensive studies of large cohorts in other regions, even low exposure to air pollutants can have health effects $[47,48]$. However, there is a lack of studies on the association between specific respiratory and circulatory diseases and different air pollutants. The effects observed in this study were shortterm effects, and studies of long-term effects still need to be conducted in coastal areas of China.

\section{Conclusions}

An association was observed between air pollutants and respiratory and circulatory outpatient visits. During the cold season, the ER of $\mathrm{NO}_{2}$ was higher than that during the warm season for both respiratory- (both upper and lower) and circulatory-related outpatient visits. However, during the cold season, $\mathrm{O}_{3}-8 \mathrm{~h}, \mathrm{NO}_{2}$ and $\mathrm{PM}_{2.5}$ had 
greater ERs for upper respiratory-related outpatient visits than for lower respiratory-related outpatient visits, and during the warm season, $\mathrm{O}_{3}-8 \mathrm{~h}, \mathrm{NO}_{2}, \mathrm{PM}_{10}$ and $\mathrm{PM}_{2.5}$ had greater ERs for lower respiratory-related outpatient visits. In the double air pollutant model, PM and $\mathrm{NO}_{2}$ showed a high correlation.

\section{Supplementary information}

Supplementary information accompanies this paper at https://doi.org/10. 1186/s12889-020-08915-y.

Additional file 1 Table S1-S4. Percentage changes with $95 \% \mathrm{Cls}$ for outpatient visits for respiratory and circulatory diseases according to air pollutants in different models.Table S5. Percentage changes with 95\% Cls for outpatient visits for respiratory and circulatory diseases according to air pollutants in the model with ozone exceeding $100 \mu \mathrm{g} / \mathrm{m}^{3}$. Fig. S1. Percentage changes with $95 \% \mathrm{Cls}$ for outpatient visits for circulatory diseases under conditions over $30^{\circ} \mathrm{C}$ and under $30^{\circ} \mathrm{C}(\mathrm{A})$. The Wilcoxon paired test was used to compared the ERs for circulatory outpatient visits between conditions over and under $30^{\circ} \mathrm{C}$ (B).

\section{Abbreviations}

AP: Air pressure; DOW: Day of the week; $\mathrm{O}_{3}-8 \mathrm{~h}$ : Daily maximum 8-h mean ozone; ERs: Excess risks; df: Degrees of freedom; GLM: Generalized linear model; ICD-10: 10th edition of the International Classification of Diseases; $\mathrm{NO}_{2}$ : Nitrogen dioxide; ns: Natural spline; $\mathrm{PM}_{10}$ : Particulate matter with an

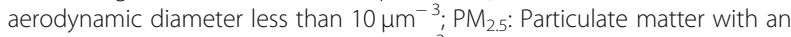
aerodynamic diameter less than $2.5 \mathrm{\mu m}^{-3}$; $\mathrm{RH}$ : Relative humidity; and T: temperature

\section{Acknowledgements}

We appreciate the support of the Fuzhou Environmental Monitoring Center Station and the Fuzhou Meteorological Bureau.

\section{Authors' contributions}

YJ, CW, XZ and BL: study concept and design; YJ, XL, QZ, SJ, XZ: data collection and supervision; JC and $Y J$ : drafting of the manuscript; JC, CW and SY: analysis and interpretation of data; $X Z$ and $B L$ : critical revision of the manuscript for important intellectual content. All authors read and approved the final manuscript.

\section{Funding}

This work was funded by the Startup Fund for Scientific Research, Fujian Medical University (grant number 2018QH1008) and Fujian Medical University's Research Foundation for Talented Scholars (grant number XRCZX2018011). The funders had no role in study design, data collection and analysis, decision to publish, or preparation of the manuscript.

\section{Availability of data and materials}

The data belongs to the Fuzhou Center for Disease Control and Prevention, and has obtained permission from the center. Moreover, data are available from the corresponding author (lby@mail.fjmu.edu.cn and sanny77@sina. com) on reasonable request.

\section{Ethics approval and consent to participate}

We only collected the total number of outpatient visits that was not contain any individual or patient data. Ethics approval and consent to participate were unnecessary for the present study in accordance with the IRB of Fuzhou Center for Disease Control and Prevention.

\section{Consent for publication}

Not applicable.

\section{Competing interests}

All authors declare that they have no competing interests.
Received: 8 October 2019 Accepted: 13 May 2020

Published online: 20 July 2020

\section{References}

1. Landrigan PJ, Fuller R, Acosta NJ, Adeyi O, et al. The lancet commission on pollution and health. Lancet. 2018;391(10119):462-512.

2. Kan H, Chen R, Tong S. Ambient air pollution, climate change, and population health in China. Environ Int. 2012;42:10-9.

3. Lu F, Xu D, Cheng Y, Dong S, Guo C, Jiang X, Zheng X. Systematic review and meta-analysis of the adverse health effects of ambient PM2.5 and PM10 pollution in the Chinese population. Environ Res. 2015;136:196-204.

4. Organization WHO. Air quality guidelines: global update 2005: particulate matter, ozone, nitrogen dioxide, and sulfur dioxide. World Health Organization. 2006.

5. Liu C, Liu Y, Zhou Y, Feng A, Wang C, Shi T. Short-term effect of relatively low level air pollution on outpatient visit in Shennongjia. China Environ Pollut. 2019:245:419-26.

6. Wang Y, Zu Y, Huang L, Zhang H, Wang C, Hu J. Associations between daily outpatient visits for respiratory diseases and ambient fine particulate matter and ozone levels in Shanghai, China. Environ Pollut. 2018;240:754-63.

7. Zhang F, Li L, Krafft T, Lv J, Wang W, Pei D. Study on the association between ambient air pollution and daily cardiovascular and respiratory mortality in an urban district of Beijing. Inter J Env Res Pub Heal. 2011;8(6): 2109-23.

8. Lamichhane DK, Kim HC, Choi CM, Shin MH, et al. Lung cancer risk and residential exposure to air pollution: a Korean population-based casecontrol study. Yonsei Med J. 2017;58(6):1111-8.

9. Hoffmann B, Luttmann-Gibson H, Cohen A, Zanobetti A, de Souza C, et al. Opposing effects of particle pollution, ozone, and ambient temperature on arterial blood pressure. Environ Health Persp. 2011;120(2):241-6.

10. Wang C, Chen R, Shi M, Cai J, et al. Possible mediation by methylation in acute inflammation following personal exposure to fine particulate air pollution. Am J Epidemiol. 2017;187(3):484-93.

11. Huang C, Moran AE, Coxson PG, Yang X, et al. Potential cardiovascular and total mortality benefits of air pollution control in urban China. Circulation. 2017;136(17):1575-84.

12. Lin $Y$, Zou J, Yang W, Li CQ. A review of recent advances in research on PM2.5 in China. Int J Environ Res Public Health. 2018; 15(3):E438.

13. Szyszkowicz M, Rowe BH, Brook RD. Even low levels of ambient air pollutants are associated with increased emergency department visits for hypertension. Can J Cardiol. 2012;28(3):360-6.

14. Peel JL, Metzger KB, Klein M, Flanders WD, et al. Ambient air pollution and cardiovascular emergency department visits in potentially sensitive groups. Am J Epidemiol. 2006;165(6):625-33.

15. Shin H, Burr W, Stieb D, Haque L, Kalayci H, Jovic B, Smith-Doiron M. Air health trend Indicator: association between short-term exposure to ground ozone and circulatory hospitalizations in Canada for 17 years, 1996-2012. Int J Environ Res Public Health. 2018;15(8):E1566.

16. Crouse DL, Peters PA, van Donkelaar A, Goldberg MS, et al. Risk of nonaccidental and cardiovascular mortality in relation to long-term exposure to low concentrations of fine particulate matter: a Canadian national-level cohort study. Environ Health Perspect. 2012;120(5):708-14.

17. Zhang S, Li G, Tian L, Guo Q, Pan X. Short-term exposure to air pollution and morbidity of COPD and asthma in east Asian area: a systematic review and meta-analysis. Environ Res. 2016;148:15-23.

18. Wang C, Feng $L$, Chen $K$. The impact of ambient particulate matter on hospital outpatient visits for respiratory and circulatory system disease in an urban Chinese population. Sci Total Environ. 2019;666:672-9.

19. Chai G, He H, Sha Y, Zhai G, Zong S. Effect of PM2. 5 on daily outpatient visits for respiratory diseases in Lanzhou, China. Sci Total Environ. 2019;649: 1563-72.

20. Bhaskaran K, Gasparrini A, Hajat S, Smeeth L, Armstrong B. Time series regression studies in environmental epidemiology. Int J Epidemiol. 2013; 42(4):1187-95.

21. Li L, Lin GZ, Liu HZ, Guo Y, Ou CQ, Chen PY. Can the air pollution index be used to communicate the health risks of air pollution? Environ Pollut. 2015; 205:153-60.

22. Gasparrini A. Distributed lag linear and non-linear models in $R$ : the package dlnm. J Stat Softw. 2011:43(8):1-20.

23. Gasparrini A, Armstrong B, Kenward MG. Distributed lag non-linear models. Stat Med. 2010;29(21):2224-34. 
24. Zhang H, Wang Y, Hu J, Ying Q, Hu XM. Relationships between meteorological parameters and criteria air pollutants in three megacities in China. Environ Res. 2015;140:242-54.

25. Li R, Wang Z, Cui L, Fu H, et al. Air pollution characteristics in China during 2015-2016: spatiotemporal variations and key meteorological factors. Sci Total Environ. 2019;648:902-15.

26. Quan J, Tie X, Zhang Q, Liu Q, et al. Characteristics of heavy aerosol pollution during the 2012-2013 winter in Beijing, China. Atmos Environ. 2014;88:83-9.

27. McGregor GR, Bamzelis D. Synoptic typing and its application to the investigation of weather air pollution relationships, Birmingham, United Kingdom. Theor Appl Climatol. 1995;51(4):223-36.

28. Duo B, Cui L, Wang Z, et al. Observations of atmospheric pollutants at Lhasa during 2014-2015: pollution status and the influence of meteorological factors. J Environ Sci. 2018:63:28-42.

29. Ma Y, Xiao B, Liu C, Zhao Y, Zheng X. Association between ambient air pollution and emergency room visits for respiratory diseases in spring dust storm season in Lanzhou, China. Inter J Env Res Pub Heal. 2016;13(6):613.

30. Zhang H, Niu Y, Yao Y, Chen R, Zhou X, Kan H. The impact of ambient air pollution on daily hospital visits for various respiratory diseases and the relevant medical expenditures in Shanghai, China. Int J Environ Res Public Health. 2018;15(3):E425

31. Zhang $P$, Dong $G$, Sun $B$, et al. Long-term exposure to ambient air pollution and mortality due to cardiovascular disease and cerebrovascular disease in Shenyang, China. Plos One. 2011;6(6):e20827.

32. Phung D, Hien TT, Linh HN, Luong LM, Morawska L, Chu C, Binh ND, Thai PK. Air pollution and risk of respiratory and cardiovascular hospitalizations in the most populous city in Vietnam. Sci Total Environ. 2016;557:322-30.

33. Zhang Y, Wang SG, Xia Y, Shang KZ, Cheng YF, et al. Association between ambient air pollution and hospital emergency admissions for respiratory and cardiovascular diseases in Beijing: a time series study. Biomed Environ Sci. 2015;28(5):352-63.

34. Sun J, Barnes A, He D, Wang M, Wang J. Systematic review and metaanalysis of the association between ambient nitrogen dioxide and respiratory disease in China. Int J Environ Res Public Health. 2017;14(6):E646.

35. Perez-Lauterbach D, Nahum R, Ahmad H, Topeff JM, Dossick D, Cole JB, Arens AM. Dose-dependent pulmonary injury following nitrogen dioxide inhalation from Kinepak ${ }^{\text {TM }}$ detonation. J Emerg Med. 2019;57(2):77-180.

36. Sun S, Cao W, Mason TG, Ran J, Qiu H, et al. Increased susceptibility to heat for respiratory hospitalizations in Hong Kong. Sci Total Environ. 2019;666:197-204.

37. Park JH, Lee SH, Yun SJ, Ryu S, Choi SW, et al. Air pollutants and atmospheric pressure increased risk of ED visit for spontaneous pneumothorax. Am J Emerg Med. 2018;36(12):2249-53.

38. Ma Y, Yang S, Yu Z, Jiao H, Zhang Y, Ma B, Zhou J. Effect of diurnal temperature range on outpatient visits for common cold in Shanghai, China. ENVIRON SCI POLLUT R. 2020;27(2):1436-48.

39. Ma $Y$, Jiao $H$, Zhang $Y$, Cheng B, Feng F, Yu Z, Ma B. Impact of temperature changes between neighboring days on COPD in a city in Northeast China. Environ Sci Pollut Res. 2019:1-9.

40. Zhao A, Chen R, Kuang X, Kan H. Ambient air pollution and daily outpatient visits for cardiac arrhythmia in Shanghai, China. J Epidemiol. 2014;24(4):321-6.

41. Yu IT, Qiu H, Wang X, Tian L, Tse LA. Synergy between particles and nitrogen dioxide on emergency hospital admissions for cardiac diseases in Hong Kong. Int J Cardiol. 2013;168(3):2831-6.

42. Luo K, Li R, Wang Z, Zhang R, Xu Q. Effect modification of the association between temperature variability and daily cardiovascular mortality by air pollutants in three Chinese cities. Environ Pollut. 2017;230:989-99.

43. Shi W, Sun Q, Du P, Tang S, Chen C, Sun Z, Wang J, Li T, Shi X. Modification effects of temperature on the ozone-mortality relationship: a nationwide multicounty study in China. Environ Sci Technol. 2020;54(5):2859-68.

44. Newby DE, Mannucci PM, Tell GS, Baccarelli AA, Brook RD, et al. Expert position paper on air pollution and cardiovascular disease. Eur J Heart Fail. 2014;36(2):83-93.

45. Baccarelli A, Zanobetti A, Martinelli I, Grillo P, Hou L, Giacomini S, et al. Effects of exposure to air pollution on blood coagulation. J Thromb Haemost. 2007;5(2):252-60

46. Li T, Zhang Y, Wang J, Xu D, et al. All-cause mortality risk associated with long-term exposure to ambient PM2.5 in China: a cohort study. The Lancet Public Health. 2018;3(10):e470-e477.

47. Beelen R, Raaschou-Nielsen O, Stafoggia M, et al. Effects of long-term exposure to air pollution on natural-cause mortality: an analysis of 22
European cohorts within the multicentre ESCAPE project. The Lancet. 2014; 383(9919):785-95.

48. Cohen AJ, Brauer M, Burnett R, Anderson HR, et al. Estimates and 25-year trends of the global burden of disease attributable to ambient air pollution: an analysis of data from the Global Burden of Diseases Study 2015. The Lancet. 2017;389(10082):1907-18.

\section{Publisher's Note}

Springer Nature remains neutral with regard to jurisdictional claims in published maps and institutional affiliations.
Ready to submit your research? Choose BMC and benefit from:

- fast, convenient online submission

- thorough peer review by experienced researchers in your field

- rapid publication on acceptance

- support for research data, including large and complex data types

- gold Open Access which fosters wider collaboration and increased citations

- maximum visibility for your research: over $100 \mathrm{M}$ website views per year

At $\mathrm{BMC}$, research is always in progress.

Learn more biomedcentral.com/submissions 